Article

\title{
Preparation of Asphalt Concretes by Gyratory Compactor: A Case of Study with Rheological and Mechanical Aspects
}

\author{
Paolino Caputo ${ }^{1}\left(\mathbb{D}\right.$, Pietro Calandra ${ }^{2, *(\mathbb{C})}$, Rosolino Vaiana ${ }^{3, *(\mathbb{D})}$, Vincenzo Gallelli ${ }^{3}(\mathbb{D}$, \\ Giovanni De Filpo ${ }^{1}\left[\right.$ and Cesare Oliviero Rossi ${ }^{1}{ }^{\circledR}$ \\ 1 Department of Chemistry and Chemical Technologies, University of Calabria, 87036 Arcavacata di Rende, \\ CS, Italy; paolino.caputo@unical.it (P.C.); defilpo@unical.it (G.D.F.); cesare.oliviero@unical.it (C.O.R.) \\ 2 CNR-ISMN, National Council of Research, Institute for the Study of Nanostructured Materials, \\ 00015 Monterotondo Stazione, RM, Italy \\ 3 Department of Civil Engineering, University of Calabria, 87036 Arcavacata di Rende, CS, Italy; \\ vincenzo.gallelli@unical.it \\ * Correspondence: pietro.calandra@cnr.it (P.C.); rosolino.vaiana@unical.it (R.V.); \\ Tel.: +39-0690672409 (P.C.); +39-0984496786 (R.V.)
}

Received: 22 October 2020; Accepted: 25 November 2020; Published: 30 November 2020

\begin{abstract}
For asphalt concrete preparation in laboratory mix-design operations, bitumens are usually mixed with micrometer-sized particles (filler), sand and centimeter-sized crushed stones in a gyratory press at a temperature of about $140-155{ }^{\circ} \mathrm{C}$ depending on the bitumen viscosity, until adequate homogenization and compaction take place (air voids optimum). This requires energy consumption. To minimize it, the process needs to be optimized and is usually made empirically. The aim of this manuscript is to gain a comprehension of the physico-chemical mechanisms involved in the process by exploring: (i) the rheological properties (viscosity, activation energy) of a neat and RTFOT-aged bitumen, in presence and in absence of a filler, (ii) the volumetric and resistance behavior under the compaction in a standard Gyratory Compactor (GC) of their blends with aggregates and (iii) the mechanical properties (Indirect Tensile Strength, compression and tensile deformation) of the final products. Correlations between activation energy and pre-exponential factor of the viscosity on a side, and between viscosity, workability and final mechanical properties on the other side allowed to provide a rational interpretation of the physico-chemical processes involved in the framework of the physics of complex fluids. The scientific clues will be of help in optimizing the workability in asphalt concretes productions with obvious repercussions in terms of energy savings, useful for economic and environmental issues.
\end{abstract}

Keywords: bitumen; filler; asphalt concretes; Arrhenius; viscosity; workability; gyratory press

\section{Introduction}

Asphalt (asphalt concrete) is a well-known material used for road paving all around the world. It is a mixture of crushed stone materials (aggregates), sand and a fine powder (filler) bound together by a small amount (about $5 \% \mathrm{w} / \mathrm{w}$ ) of a viscoelastic binder called bitumen [1,2]. These components need to be properly mixed together, and this is usually made at relatively high temperatures $\left(140-155^{\circ} \mathrm{C}\right)$. The mechanical and thermal energy consumption to complete this job unavoidably implies high costs.

To face this problem, mechanical properties of bitumens are tuned by small amounts of additives [3]. Usually organic additives, chemical additives [4-6], surfactants [7] and also foaming techniques are adopted [3]. This can be also useful to reduce the temperature at which the asphalt is prepared [8]. This approach is quite interesting since it is able to effectively reduce the emission of greenhouse gases 
in the atmosphere $[9,10]$ to such an extent that the European Asphalt Industry recommend of the use of Warm Mix Asphalt [11,12] as well as the dosages for several WMA additive products [13-19].

In this method, typically in laboratory mix-design operations, bitumens are mixed with the sand, crushed stones and finally with filler and compacted by a gyratory compactor (GC), at a temperature of $140-155{ }^{\circ} \mathrm{C}$ (depending on the bitumen viscosity) until adequate compaction/homogenization takes place.

The easiness of compacting the mixture is generally referred to as workability which is usually correlated also to the easiness of handling and paving. Good workability is a very important and desired characteristic, not only because it can reduce the energy consumption required for mechanically homogenizing the mixture with clear repercussions in terms of costs, but also because higher workability usually implies higher compactibility among all the components, which is important during construction and has a direct effect on performance of asphalt mixtures [20,21]. A good workability (and compactibility) leads to reduction of the mix air voids during the mixing process, provides aggregates interlock, eventually improves the final asphalt layer stiffness, and increase its moisture resistance. Compaction of mixes was found to depend on aggregate gradation in term of nominal maximum aggregate size (NMAS) [22], on the type, shape, and texture of aggregate [23,24], content and lithological nature of filler [25-28]; mixing and compaction temperature are related to content, grade and type of bitumen [24,29] and on indoor compaction methods [30-32].

The knowledge, comprehension and control of these factors are fundamental to make predictions on the workability and compatibility of an asphalt concrete containing both fresh and recycled bitumens and to minimize the energy consumption in asphalt concretes productions with clear benefits in terms of economy and environmental issues. In this framework, the rheological properties of bitumen are of pivotal importance not only for giving easiness of compaction, but also for obtaining a high quality of the final road pavement, since their time and temperature dependences [33-35] dictate the need for a compatibility with the specific geographical and climatic conditions [36].

It is our strong belief that such rheological properties must be fully understood at the molecular level to have a complete comprehension of the macroscopic phenomena. Indeed, we strongly support the use of sophisticated techniques for bitumen characterization [37,38], aiming at fully understanding the complex organization of the components $[39,40]$ and how it is related to the final properties, viscosity in particular [41]. However, the advanced physico-chemical approach of material science must be adapted to and conciliated with the engineering approach for asphalt preparation and paving which unavoidably needs standardized procedures under shared regulations. So, in the present work, we try to synergistically investigate (i) the rheological characteristics of fresh and aged bituminous materials under the framework of the physics of complex fluids and (ii) the engineering aspects of asphalt productions (compaction process parameters and final mechanical properties) to shed light on how the rheological properties of bitumen can be related to the workability and the mechanical properties of the final asphalt.

To do this, we measured the rheological properties of neat and RTFOT aged binder and their mixtures with filler and prepared samples of asphalt concretes by gyratory compactor GC monitoring the compaction process (resistance to flow and sample density change) and observing the final mechanical characteristics.

Correlation between rheological properties, workability and final mechanical characteristics will allow understanding the physical principles at the molecular basis governing the workability of the mixture in a gyratory press and its strength under mechanical deformation in the final product.

\section{Experimental Part}

\subsection{Neat and RTFOT-Aged Bitumens}

Neat bitumen was kindly supplied by Loprete Costruzioni Stradali - Terranova Sappo Minulio-Calabria-Italy. It has a 50/70 penetration grade, measured by usual standardized procedure 
ASTM D946 [42]. It was reported that the four different portions (Saturates, Aromatics, Resins and Asphaltenes) [43] determined by the S.A.R.A. method [44], had concentrations of 3.8, 51, 21.5, $23.4 \mathrm{w} / \mathrm{w} \%$ respectively. The asphaltene content was judged compatible with the 50/70 grade.

The same bitumen was subjected to ageing by the RTFOT (Rolling Thin-Film Oven Test) procedure. In the present work, the standard RTFOT procedure was extended up to $225 \mathrm{~min}$ (normally it is $75 \mathrm{~min}$, according to ASTM D2872-04) to obtain a bitumen (identified in the present work as "RTFOT-Aged Bitumen") rigid enough to simulate a prolonged ageing process of about 10-12 years, which is a period typical of recycled asphalts.

The Penetration grade (EN 1426:2015) and ring and ball test results (EN 1427:2015) on neat and RTFOT-aged bitumen are reported in Table 1.

Table 1. Penetration grade and ring and ball test results.

\begin{tabular}{ccc}
\hline BITUMEN & $\begin{array}{c}\text { Penetration }(\mathbf{d m m}) \\
( \pm \mathbf{1})\end{array}$ & $\begin{array}{c}\text { Ring and Ball }\left({ }^{\circ} \mathbf{C}\right) \\
( \pm \mathbf{1})\end{array}$ \\
\hline Neat & 66 & 48 \\
RTFOT-Aged & 27 & 59 \\
\hline
\end{tabular}

The viscosity measurements were conducted using a stress controlled rheometer (SR5000, Rheometric Scientific, Piscataway, NJ, USA) equipped with a parallel plate geometry (gap $2 \mathrm{~mm}$, diameter $25 \mathrm{~mm})$. The temperature was controlled by a Peltier apparatus $\left( \pm 0.1^{\circ} \mathrm{C}\right)$. The viscosity was measured in the temperature range $100-140^{\circ} \mathrm{C}$. Steady flow experiments were performed in a shear rate range $0.02-1000 \mathrm{~s}^{-1}$. The minimum and the maximum torque that our instrument can measure are 0.02 and $100 \mathrm{~g} \cdot \mathrm{cm}$ respectively. To be sure that the steady flow takes place in the samples, the flow equilibrium time was measured by transient experiments (step-rate test) and it was observed that $10 \mathrm{~s}$ was a time sufficient to ensure the steady flow in the system for the overall investigated shear rate range. The variation of viscosity versus shear rates for samples was measured. It was observed that all samples have Newtonian rheological behaviors, which means that the viscosity is independent of shear rates.

\subsection{Aggregates Materials: Gradation and Main Properties}

Limestone aggregate with a nominal aggregate size of $12.5 \mathrm{~mm}$ was used for both mixtures. The main aggregate properties are listed in Table 2.

Table 2. Main properties of coarse and fine aggregates.

\begin{tabular}{lccc}
\hline Aggregate Type & Test/Index & Value & Standard \\
\hline \multirow{2}{*}{ Coarse Aggregate } & Aggregate nature & Limestone & - \\
& Los Angeles Abrasion Test [\%] & 21 & EN 1097-2 (2010) \\
& Shape Index [\%] & 26 & EN 933-4 (2008) \\
& Aggregate density [g/cm $\left.{ }^{3}\right]$ & 2.772 & EN 15326 (2009) \\
Fine Aggregate & Aggregate nature & Limestone & - \\
& Sand Equivalent Test [\%] & 94 & EN 933-8 (2012) \\
& Fine Aggregate Angularity Index [\%] & 46 & ASTM C1252 (2006) \\
& Filler Stiffness Power (filler/binder $=1.5)$ & $8{ }^{\circ} \mathrm{C}\left({ }^{\circ}\right)$ & EN 13179-1 (2013) \\
\hline
\end{tabular}

Weighed amounts of various sieve passages were used for the preparation of all the asphalt concretes. This procedure allowed rendering the size distribution as invariant in all our experiments. The particle size distribution is reported in Figure 1 (solid circles): it should be noted that the design aggregate gradation is an average distribution between the upper and lower specification limits (crosses) for surface courses, according to the Italian Standard Specifications [45]. This aggregate 
gradation also meets the limits imposed by the Superpave SHRP [46] which identifies a restricted zone for the rutting problem (gray area): it can be noted that sand content in our mixture falls conveniently below such area.

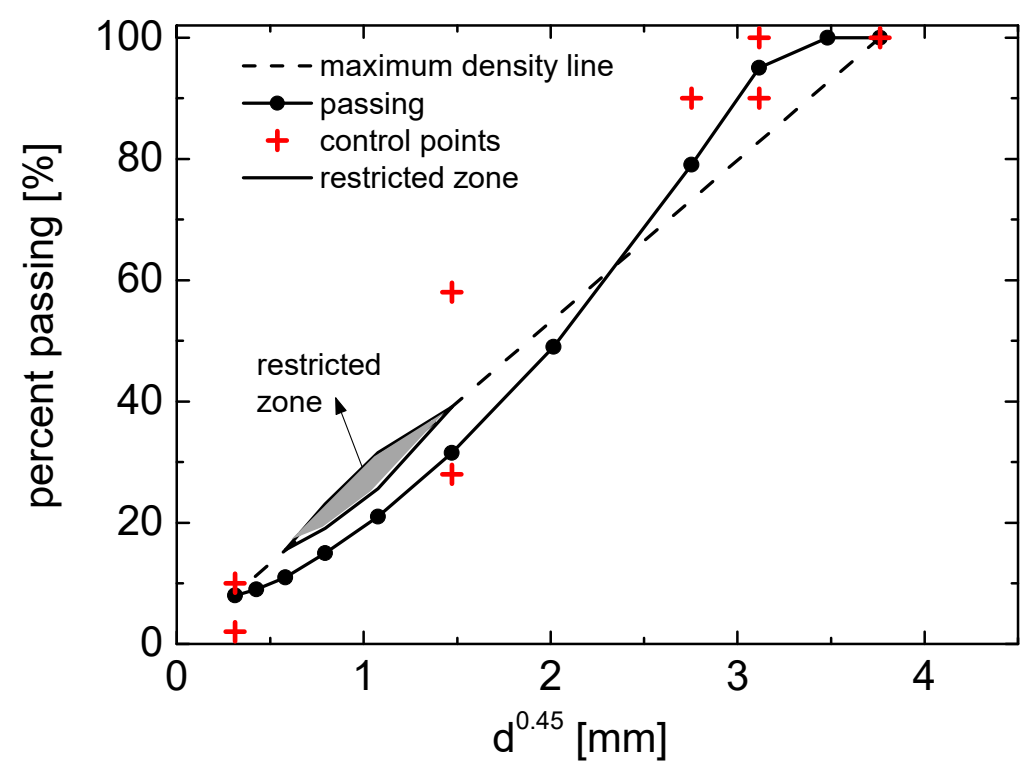

Figure 1. Aggregate gradation used for the asphalt concretes specimens' productions.

The process of grinding the limestone coarse aggregates produced fine powder which was sieved to select those particles with size $<75 \mu \mathrm{m}$. They were used as the filler for asphalt concretes preparation.

\subsection{Preparation of Asphalt Concretes Specimens: Volumetric Analysis by Gyratory Compactor (GC) and Indirect Tensile Strength (ITS)}

Asphalt concrete specimens were prepared by mixing the bitumens described in Section 2.1 with the mineral aggregates described in Section 2.2 (bitumen $4 \mathrm{w} / \mathrm{w} \%$; filler $7 \mathrm{w} / \mathrm{w} \%$, aggregates $89 \mathrm{w} / \mathrm{w} \%$ ) and compacting the mixtures following the Gyratory compaction method according to the EN 12697-31 (UNI EN 2007), under a constant pressure of $600 \mathrm{kPa}$, with a rotational speed of $30 \mathrm{rpm}$, a nominally constant angle of gyration $1.25^{\circ}$ and a temperature of $155^{\circ} \mathrm{C}$.

Note that GC is an established practice of dense-volumetric based analysis of asphalt mixes [46].

In the procedure, the volume of the sample within the compactor is continuously measured as a function of time during compaction. From this, knowing the volumetric properties of the individual components (aggregate and bitumen) makes it possible to trace the density variation $\%(\% \mathrm{Gmm})$ of the mix, as well as other quantities like Void Air (Va), Void in Mineral Aggregates (VMA), voids filled with asphalt (VFA) and other indicators, which are shown in Appendix A together with their physical meaning (CDI, TDI, CFI, TFI). Generally, the compaction criteria by GC focus on the volumetric parameters above mentioned in correspondence to three characteristic points during the compaction effort: an initial (Nini), design (Ndes), and maximum (Nmax) number of gyrations.

In all specimens, the bitumen amount was $4 \mathrm{w} / \mathrm{w} \%$ because this composition maximizes the stability of the final product as found by routine Marshall stability tests (compaction energy of 75 pestle blows for each side of the specimen-EN 12697-30) carried out at various compositions. The results of Marshall stability tests for asphalt concretes prepared with neat and RTFOT-Aged Bitumen are reported in Table 3. The table shows that aged bitumen has an increase in Marshall Quotient (Marshall Stiffness), as expected. 
Table 3. Marshall Stability for asphalts concretes prepared with neat and RTFOT-Aged Bitumen (average of six independent samples). In parenthesis the standard deviation is reported.

\begin{tabular}{cccc}
\hline & Neat Bitumen Mix & $\begin{array}{c}\text { RTFOT-Aged } \\
\text { Bitumen Mix }\end{array}$ & $\begin{array}{c}\text { Acceptance } \\
\text { Thresholds [45] }\end{array}$ \\
\hline bulk density $\left(\mathrm{g} / \mathrm{cm}^{3}\right)$ & $2.481 \pm 0.005$ & $2.465 \pm 0.005$ & - \\
Marshall Stability $(\mathrm{KN})$ & $11.9 \approx \pm 0.4$ & $13.0 \pm 0.4$ & $>11$ \\
Flow $(\mathrm{mm})$ & $2.5 \pm 0.2$ & $1.9 \pm 0.2$ & - \\
Marshall Quotient $(\mathrm{KN} / \mathrm{mm})$ & $4.8 \pm 0.5$ & $6.8 \pm 0.5$ & $>3$ \\
\hline
\end{tabular}

Mechanical performance of the final product obtained after 120 gyrations were finally assessed in terms of Indirect Tensile Strength (ITS) in accordance with the EN 12697-23.

\section{Results and Discussion}

To highlight the rheological properties of bituminous materials used in this study, viscosity ( $\mathrm{\eta}$ ) was measured as a function of temperature for both neat and RTFOT-aged as they are and mixed with filler. The first aim of this study is to understand the macroscopic behavior in terms of molecule-based physics, so it must be pointed out that viscosity is a synthetic indicator concisely yielding information on the total amount of energy that the system absorbs under shear conditions. It has the physical meaning of representing the resistance to flow.

The temperature dependence of $\eta$ is reported in Figure 2 as $\ln \eta$ vs. 1000/T (Arrhenius plot). The choice of the Arrhenius plot does not follow the common habit to show the temperature dependence of a dynamical property. Arrhenius-like approach in fact, is simple and informative for a wide range of processes (viscosity, diffusion, conductivity, relaxation times etc.) [47-50], but in our case it is the result of our approach based on the molecular interpretation of the macroscopic properties. The arguments are reported in a recent study [51] and will not be extensively presented here. Here instead, it is enough to notice that although the fluids under study cannot be considered as simple liquids and despite other methods being available [52-54], the linear trend in the Arrhenius plot suggests the effectiveness of the two-wells potential model, at least in the considered temperature range. This allows to safely extract both the activation energy $(E a)$ and the pre-exponential factor $(\ln A s)$ by fitting of the experimental data through the plot of $\ln \eta(T)$ vs. 1000/T according to the Equation (1) (Ea/R is the slope of the fitting curve and $\ln A s$ is the intercept):

$$
\ln \eta(T)=\ln A s+\frac{E a}{R} \cdot \frac{1000}{T}
$$

where $\eta$ is the viscosity and $R$ is the gas constant $\left(R=8.314 \mathrm{~J} \mathrm{~K}^{-1} \mathrm{~mol}^{-1}\right)$.

Figure 3 reports the $E a$ (abscissa) and $\ln A s$ (ordinates) for the various samples, a representation allowing to detect the correlation between the two quantities (dashed line). In the Arrhenius model framework, $E a$ and $A s$ have precise physical meanings. In fact, although the Arrhenius model has been derived from the reaction kinetics in the gas phase, a favored theoretical base for the interpretation of viscosity has been provided by the application of the transition-state-theory [55] (TST) by Eyring of Arrhenius chemical kinetics to transport phenomena [56]. TST basically explains the reaction rates of elementary chemical reactions assuming a chemical quasi-equilibrium between reactants and an activated transition state complex. 


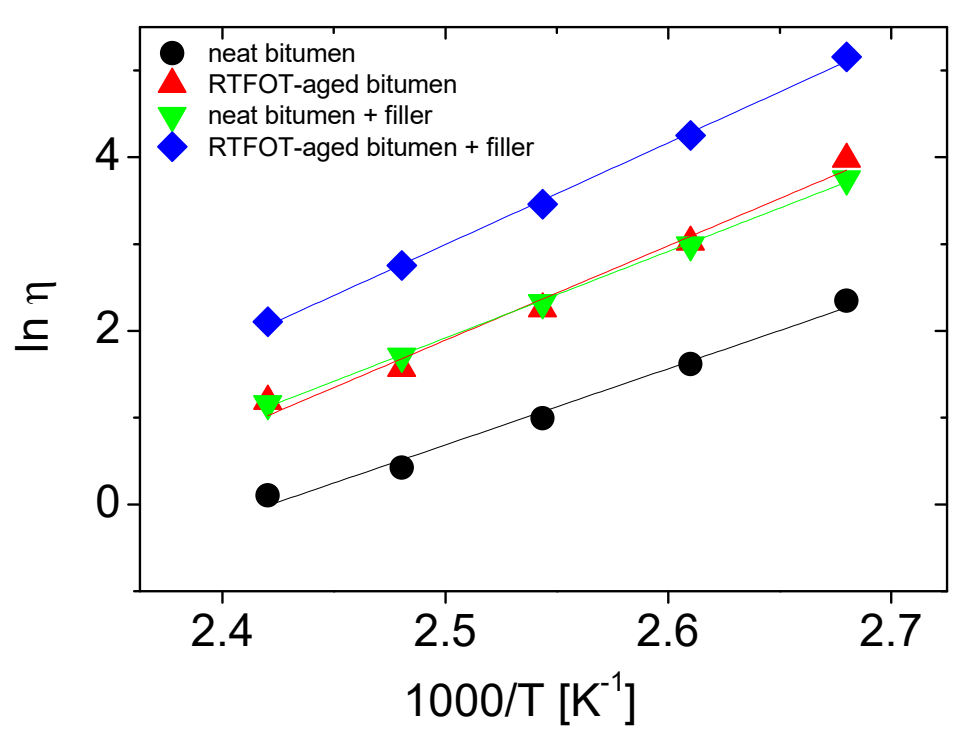

Figure 2. Arrhenius plot of the investigated samples. Uncertainties associated to the data are at most of the same order of the point size.

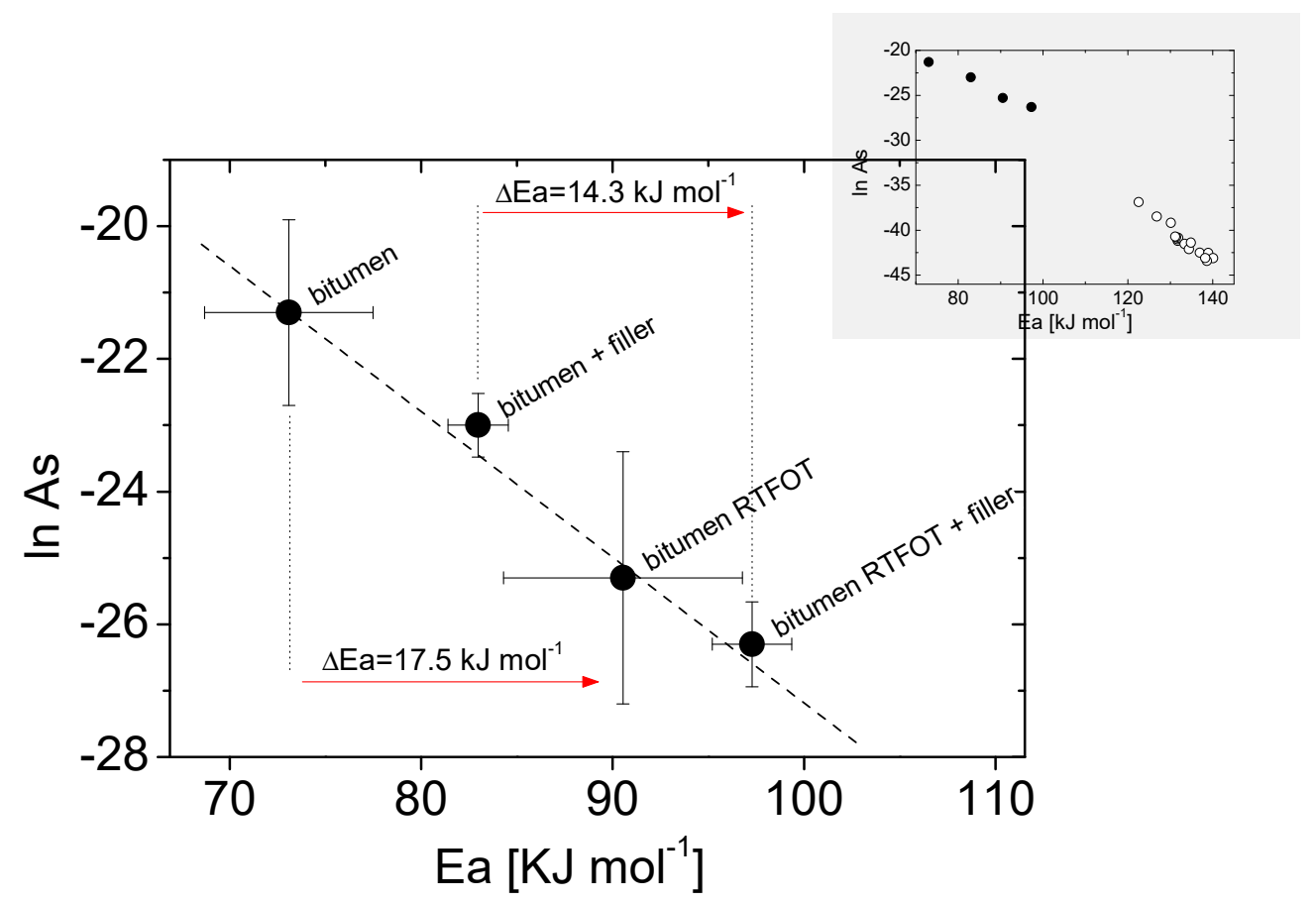

Figure 3. Correlation between the pre-exponential factor (ln As) and the activation energy (Ea). The dashed line is the linear regression of the experimental data $(R=0.986)$. In the inset, the data of the present paper (closed symbols) are shown together with those taken from literature (open symbols).

We will comment on $E a, \ln A s$ and their correlation separately in the following sections.

\subsection{Activation Energy (Ea) and Pre-Exponential Factor (ln As)}

In the transition-state-theory (TST) context, $E a$ represents the activation energy to overcome for flowing to occur. In our samples, the $E a$ values are of the order of a hundred $\mathrm{kJ} \mathrm{mol}^{-1}$ and are consistent with the values observed for other additivated bitumens [57] at room temperature. In our samples, due to the high temperature, the bitumens are entirely in the liquid state $\left(G^{\prime} \approx 0\right)$ so a more disaggregated form with respect to the typical bitumens at room temperature is present. 
In this situation, it can be expected that the activation energy for flowing is lower than that at room temperature. From Figure 3, it can be noticed that:

(1) the filler-containing samples have higher viscosities than the corresponding neat samples, as expected for such kind of samples;

(2) the RTFOT ageing causes an increase in viscosity: this increase is of $17.5 \mathrm{~kJ} \mathrm{~mol}^{-1}$ for the neat bitumen, and of about $14.3 \mathrm{~kJ} \mathrm{~mol}^{-1}$ for the bitumen + filler.

As for the pre-exponential factor, $A s$ has the meaning of a frequency factor, representing the fraction of effective collisions which are able to turn into the flow process. Its low value indicates a low number of effective molecular collisions which are able to turn into the flowing process [58]. In the TST context, the negative value of $\ln A s$ indicates a negative entropy of formation of the activated state during flow. All these findings are in agreement with the complex structure of the bitumen, the presence of high molecular mass molecules and the low viscosity.

\subsection{Correlation between Ea and $\ln A s$}

The linear correlation between pre-exponential factor and the activation energy is clear $(R=0.986$ and residual sum of squares $=0.39$ ). This correlation has been already noticed in a previous work dealing with polysaccharide-reinforced bitumens [57] and even in simple liquids. This is an important aspect also for applicative purposes: in fact, although there is no theory explaining such correlation [59] and if this correlation holds, then the temperature dependence of the viscosity of our materials can be expressed through one parameter only — the only one known (Ea or As)—and since the other can be derived from it, it is a fact which can be surely helpful for practical uses. Our data are compared, in the inset of Figure 3, with the data of other literature works dealing with polysaccharide-additivated bitumens at working temperature $\left(50{ }^{\circ} \mathrm{C}\right)$ [57].

The present work interestingly shows a nice consistency between the two sets of data, extending the number and types of systems for which this linear correlation holds, and suggesting a quite universal behavior. The data of the present paper thus reinforce our general view of fluids, where the key ingredients dictating rheological behavior lie at the molecular basis in the same way for different systems despite obvious specific differences at the macro-scale. For this reason, the data shown in this manuscript can be used for deeper theoretical investigation opening the way to the construction of a proper model describing why different fluids share similar rheological behavior.

\subsection{Volumetric Analysis by Gyratory Compactor}

In a gyratory compactor, the bitumen, the filler, and the macro-sized particles are homogenized and compacted through continuous stirring of the mixture allowing elimination of voids. In the procedure, the volume of the sample within the compactor and the shear resistance are continuously measured as a function of time (or number of gyrations). The volumetric data, in function of gyrations allowing the reconstruction of curves for the following main parameters:

- Density variation (\%Gmm);

- $\quad$ Air voids content (\%Va);

- $\quad$ Voids in mineral aggregate (\%VMA);

- $\quad$ Voids filled with asphalt (\%VFA).

They are reported in Tables 4 and 5 and Figure 4a for the preparation of asphalt concrete specimens with neat and RTFOT-aged bitumens. Apparently, the values shown in Tables 4 and 5 describe the two concrete asphalt mixes as overlapping. In the real sense, the focus of this study is concentrated between Nini and Ndes where the real workability of the mixes is manifested and has a major effect on compaction attitude. 
Table 4. Density variation and air voids content at different gyration levels for neat bitumen asphalt.

\begin{tabular}{cccccc}
\hline \multicolumn{5}{c}{ Neat Bitumen } \\
\hline $\begin{array}{c}\text { Number of } \\
\text { Gyrations }\end{array}$ & \%Gmm & \%VMA & \%VFA & \%Va & Acceptance Thresholds [45] \\
\hline Nini $=10$ & 84.0 & 26 & 38 & 16 & $11-15$ \\
$\mathrm{~N}_{\mathrm{LP}}=63$ & 92.0 & 19 & 57 & 8 & - \\
Ndes $=120$ & 94.3 & 17 & 66 & 6 & $3-6$ \\
Nmax $=210$ & 96.1 & 15 & 74 & 4 & $\geq 2$ \\
\hline
\end{tabular}

Table 5. Density variation and air voids content at different gyration levels for bitumen RTFOT asphalt.

\begin{tabular}{cccccc}
\hline \multicolumn{5}{c}{ RTFOT-Aged Bitumen } \\
\hline $\begin{array}{c}\text { Number of } \\
\text { Gyrations }\end{array}$ & \%Gmm & \%VMA & \%VFA & \%Va & Acceptance Thresholds [45] \\
\hline Nini $=10$ & 84.9 & 25 & 39 & 15 & $11-15$ \\
$\mathrm{~N}_{\mathrm{LP}}=54$ & 92.0 & 19 & 57 & 8 & - \\
Ndes $=120$ & 94.9 & 16 & 68 & 5 & $3-6$ \\
Nmax $=210$ & 96.5 & 15 & 76 & 3 & $\geq 2$ \\
\hline
\end{tabular}

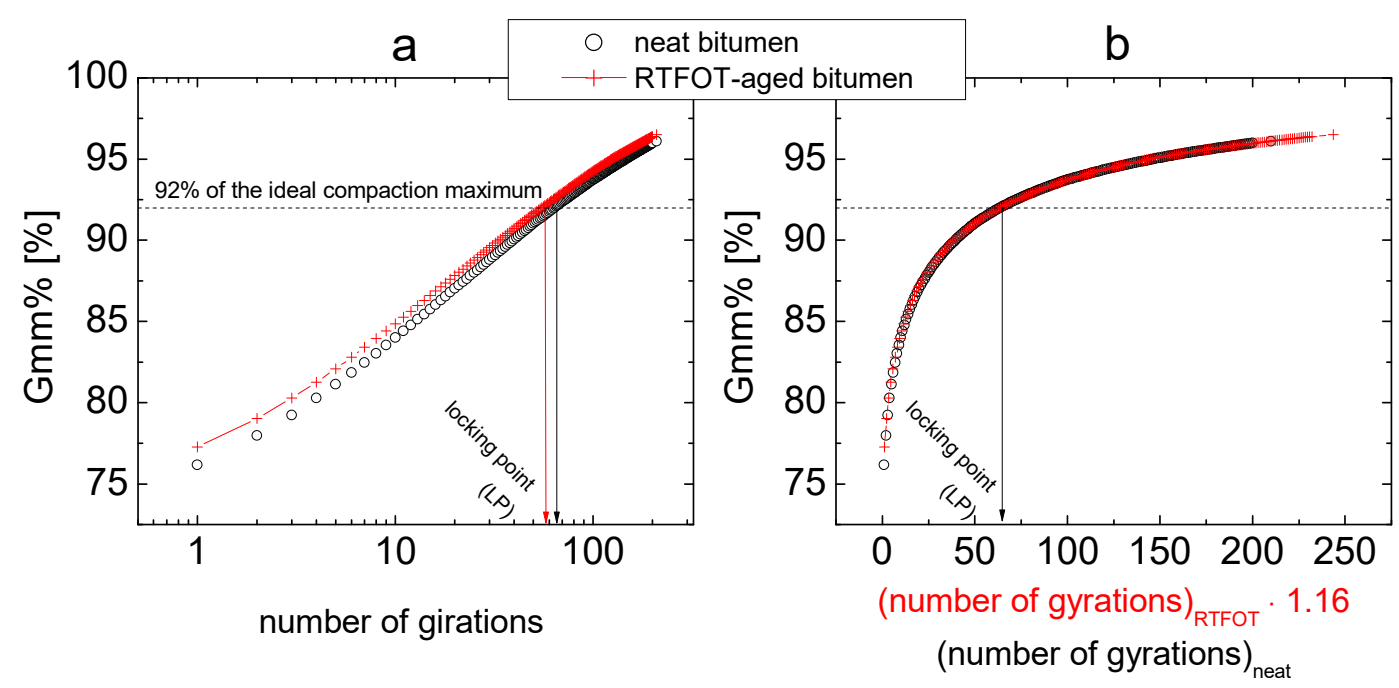

Figure 4. Gmm\% as a function of the number of gyrations. Panel (b) shows he same data of panel (a) with scaled $x$-values.

From these curves, and also from the shear resistance values as a function of gyrations, important indicators can be derived. They are described in Appendix A. Among these, in this study, the locking point (LP) is of particular interest and is defined as the number of gyrations beyond which asphalt mixture compaction and the aggregate structure become stable. Beyond this point, further compaction does not contribute much to the increase in mixture density and can even damage aggregate particles [60]. In fact, in terms of air voids (Va) for the two mixtures, Tables 4 and 5 show that from $\mathrm{N}_{\text {ini }}$ to $\mathrm{N}_{\mathrm{LP}}$ there is a decrease of about 8 percentage units corresponding to an increase in the number of gyrations of 53 (for Neat Bitumen) and 44 (for Aged Bitumen), respectively; while from $N_{L P}$ to $\mathrm{N}_{\max }$, it is evident that the number of gyrations approximately triples to obtain the same decrease of Va (approximately 8 percentage units).

In this study, the locking point is assumed to be the number of gyrations required to obtain $92 \%$ (\%Gmm) of the "ideal" compaction maximum. The different compaction grade (as a result of a possible different workability) of each system allows the reaching of LP at a different number of gyrations so the LP is system-specific (see Figure 4a showing graphically the derivation of locking point). 
It must be noted that a lower LP value means better workability since a lower number of gyrations are required to obtain the same degree of compaction. To take into account for the "way" in which this degree of compaction is reached during press rotation, another parameter is considered, the compaction densification index (CDI) whose derivation and meaning is reported in Appendix A. The derived LP and CDI values are reported in Table 6.

Table 6. Compaction Densification and Compaction Force Indexes.

\begin{tabular}{cccc}
\hline Index & Neat Bitumen Mix & RTFOT-Aged Bitumen Mix & Ratio \\
\hline Locking point (LP) & 63 & 54 & 1.16 \\
CDI & 5528 & 4747 & 1.16 \\
TDI & 378 & 451 & 0.84 \\
CFI [kN m $\left.{ }^{-2}\right]$ & 24,930 & 21,540 & 1.16 \\
TFI $\left[\mathrm{kN} \mathrm{m}^{-2}\right]$ & 65,370 & 70,590 & 0.93 \\
\hline
\end{tabular}

The different behaviors of the two mixtures can be rationalized in terms of differences in efficiency of mechanical energy transfer from the press to the inner structure of the mixture. If this perception is correct, then the number of revolutions of each sample could be scaled down for a factor accounting for this system-specific efficiency in energy transfer to give a unique common master-curve. The coincidence of the two curves is actually found if the abscissa values for the mixture containing the RTFOT bitumen is multiplied by a factor 1.16 (see Figure $4 \mathrm{~b}$ ). This means that each revolution of the gyratory press compacting the RTFOT bitumen/filler/particles has a 1.16 times more efficient compaction effect as compared to the neat bitumen/filler/particles.

Interestingly, the same ratio (1.16) is found if the compaction densification indexes and the locking points are considered:

- $\quad$ being CDI for the neat bitumen $=5,528$ and CDI for the RTFOT-aged bitumen $=4,747$, their ratio is $5,528 / 4,747=1.16$;

- $\quad$ being LP for the neat bitumen $=63$ and LP for the RTFOT-aged bitumen $=54$, their ratio is $63 / 54=1.16$.

All these clues however are a geometrical consequence of the fact that the two curves have inherently the same shape as evidenced in Figure $4 \mathrm{~b}$ where the scaling factor is considered, which further suggests that the physical principle behind the process must be universal. Another important consequence reflects on the so called "traffic densification index" (TDI, see Appendix A for its derivation). It is an integral of the curve between LP and a maximum number of revolutions (Nmax), in this study taken as Nmax $=210$ [45], so it is considered as indicator of the stability of the compacted mixture under traffic load [61]. However, taking into account that the compaction curves can be $x$-scaled according to the efficiency of compaction to give a unique curve, also the "maximum" number of revolutions should be scaled if comparisons are to be made.

Some samples can be more efficient in the compaction process than others so a unique maximum number of revolutions for them means that at the end of the process, the two mixtures will be at different degrees of compaction. With this observation, it can be argued that keeping Nmax as constant renders the derived TDI meaningless from the physical point of view. Indeed, this is not the case for our samples as the ratio of the TDI for bitumen and aged bitumen is $378 / 451=0.84$ i.e., markedly different from the value of 1.16. It must be also noted that the TDI value for the neat bitumen is lower than that for RTFOT-aged bitumen, and is an obvious consequence of the fact that the compaction curve of the former is "in delay" as compared to that for the latter.

Furthermore, these considerations probably constitute the physical basis why, in ref [46], different Nmax (or Nini and Ndes) are considered depending on the level of traffic and the maximum air temperature in operating condition. From this viewpoint, the same considerations can be made about the values indicated of $\mathrm{Ni}(\mathrm{I}=\mathrm{ini}$, des, $\max )$ by [46] which are increased by 10 and 20 revolutions if a modified bitumen by polymers with soft $(\approx 3 \%)$ or hard $(\approx 5 \%)$ modification is used, respectively [62]. 
Such considerations can be important for a better comprehension of the compaction process and can be useful for the piloted design of optimized processes.

In our opinion, the physical origin of the higher efficiency in compaction when aged bitumens are employed must be searched for in the rheology involved in the transport properties of these materials. The higher viscosity possessed by RTFOT-aged bitumens-both with filler and without it—compared to the corresponding neat bitumens allows a higher momentum transfer during shear through intermolecular interactions. This turns up in a better energy and momentum propagation within the sample under compaction in the gyratory press and therefore a more efficient process, turn by turn. The stronger intermolecular interactions present in RTFOT-aged samples cause also a higher activation energy, which is the energy barrier at the molecular level that must be overcome by the gyratory press for the flow to occur. Interestingly, it can be noticed that the ratio between the activation energies for the neat bitumen/filler and RTFOT-aged bitumen/filler (which are usually indicated as the basic mixtures undergoing compaction with the mineral aggregates so that the rheological properties are usually referred to these $[63,64])$, is $97.3 / 83=1.17 \pm 0.03$ which is recurrently within the range of experimental uncertainty as the same number was arrived at previously.

Coherently, the quantities derived from the shear resistance values (CFI and TFI, see Appendix A for their derivation) also follow this behavior. In fact, the ratio of the CFI values is $24,930 \mathrm{kN} \mathrm{m}^{-2}$ / $21,540 \mathrm{kN} \mathrm{m}^{-2}=1.16$ whereas the ratio of TFIs, (involving the integral up to Nmax) is $65,370 \mathrm{kN} \mathrm{m}^{-2}$ / $70,590 \mathrm{kN} \mathrm{m}^{-2}=0.93$. All these ratios are reported in Table 6 for a schematic panorama.

Of course, more samples need to be investigated to validate our hypothesis and more studiesboth experimental and theoretical are needed to better define the correlation between workability in the gyratory press and rheological properties.

Finally, the indirect tensile stress (ITS) values of the asphalt with neat bitumen are lower than those ones registered for the mix with bitumen RTFOT as reported in Table 7. In particular, Table 7 shows the increase in ITS and CTI resistance accompanied by a decrease in compressive deformability from neat vs. aged bitumen, highlighting the increase in viscosity of the bitumen due to aging by RTFOT, as expected. Note that ITS test is a measure of bitumen adhesion to mineral aggregate and the internal bitumen cohesion. It is determined by both mechanical factors (the degree of moistening and dust of the aggregate, the micro-texture of the aggregate, the granulation of the mineral mix) and the physicochemical-chemical nature of aggregate (acidic, alkaline, in-between) as well as the physicochemical properties of the bitumen, such as viscosity and adhesion $[65,66]$.

Table 7. Indirect Tensile Strength at $25{ }^{\circ} \mathrm{C}$ for the two mixtures (average of six independent samples compacted to Ndes $=120$ ). In parenthesis the standard deviation is reported.

\begin{tabular}{ccccc}
\hline & $\begin{array}{c}\text { Standard } \\
\text { Deviation }\end{array}$ & $\begin{array}{c}\text { Neat Bitumen } \\
\text { Mix }\end{array}$ & $\begin{array}{c}\text { RTFOT-Aged } \\
\text { Bitumen Mix }\end{array}$ & $\begin{array}{c}\text { Acceptance } \\
\text { Thresholds [45] }\end{array}$ \\
\hline Indirect Tensile Strength $\left[\mathrm{N} / \mathrm{mm}^{2}\right]$ & $(0.05)$ & 1.03 & 1.72 & $>0.7$ \\
ITS Coefficient [N/mm $\left.\mathrm{mm}^{2}\right]$ & $(25)$ & 177 & 390 & $>65$ \\
Compression deformation $[\mathrm{mm}]$ & $(0.1)$ & 1.0 & 0.7 & - \\
Tensile deformation $[\mathrm{mm}]$ & $(0.02)$ & 0.28 & 0.25 & - \\
\hline
\end{tabular}

This investigation can be a good starting point for deriving a proper model. This would have great importance for optimizing the conditions in asphalt concretes preparation and related processes, with enormous benefits in terms of energy saving and environmental concerns.

\section{Conclusions}

We found that a common scaling is observed in different bitumens for different properties, suggesting a somehow universal behavior: (i) the activation energies correlate with the pre-exponential factors, interestingly connecting the rheological behavior of bitumens with that of simple liquids; (ii) activation energies of different bitumens scales as their with workability (locking points (LP), 
compaction densification index (CDI) and compaction force index (CFI) do; (iii) compaction curves can be scaled for the different efficiency in the compaction process to obtain a common master-curve. All these apparent coincidences have been interpreted as a single consequence of a unique cause: the mere difference in the momentum and energy transport at the nanoscale between samples.

Although it is generally expected that neat bitumen should have better workability than the RTFOT-aged bitumen mix, with our work we demonstrated the opposite: stiffer bitumens, with higher viscosity and higher activation energy of viscosity (Figure 3), can propagate momentum better (definition of viscosity) and therefore the Energy transfer from the press to the inner structure of the bitumen is favored with respect to less viscous bitumens.

Our approach is actually a new way of interpreting mechanical processes for preparing asphalt concretes which obviously needs further confirmation through the study of other systems. The same scaling shared by different properties can help in optimizing the compaction process and therefore the energy consumption involved, with important consequences for applicative and economic viewpoints and environmental concerns.

Author Contributions: P.C. (Paolino Caputo) investigation, methodology, conceptualization; P.C. (Pietro Calandra) writing, conceptualization, methodology; R.V. funding acquisition, methodology, conceptualization; V.G. investigation, methodology, conceptualization; G.D.F. methodology, conceptualization; C.O.R. supervision. All authors have read and agreed to the published version of the manuscript.

Funding: This research received no external funding.

Acknowledgments: The activities of this study are part of PRIN2017 project "Urban safety, sustainability, and resilience: 3 paving solutions, 4 sets of modules, 2 platforms". Acronym: USR342. (Prot. 2017XYM8KC) whose opportunity is gratefully acknowledged. Furthermore, the Authors want to acknowledge Abraham A. Abe for his suggestions on formal aspects of the manuscript.

Conflicts of Interest: The authors declare no conflict of interest.

\section{Appendix A}

The gyratory compactor records specimen density variation and shear resistance continuously in relation to a given starting point. These compaction and resistive effort curves allow to evaluate mix resistance respectively to densification and to traffic loads calculating specific densification indexes $[60,61,67-69]$.

These curves can be divided into two zones, each one related to different asphalt mix performances (Figure A1). Furthermore, densification indexes (Compaction Densification Index, CDI, and Traffic Densification Index, TDI) are related to the energy required for reducing the air voids or changing volume of the asphalt mixture and can be calculated by integration [18,70].

As regards the resistive effort curves, two other indexes can be defined: the Compaction Force Index, CFI, and the Traffic Force Index, TFI (Figure A1); both of them are related to mix stability and they are used to describe mix resistance to distortion (shear resistance). The resistive effort $w$ is calculated as follows:

$$
w=\frac{4 P e \theta}{A h}
$$

where $e(\mathrm{~m})$ is the eccentricity of the resultant force, $p$ is the magnitude of the resultant force $(\mathrm{kN}), \theta$ is the angle of tilting $(\mathrm{rad})$, and $A\left(\mathrm{~m}^{2}\right)$ and $h(\mathrm{~m})$ represent the area and the height of the specimen, respectively.

The parameter $w$ has a unit of stress $(\mathrm{kPa})$ and it represents the work done by the compactor per unit volume per gyration, assuming the material perfectly viscous or plastic [71]. The area between the function \% $\mathrm{Gmm}(n)$, ranging from Nini (10 gyrations) to N92, corresponds to the $92 \%$ of maximum theoretical density: it can be defined as the "construction effort". The $92 \% \mathrm{Gmm}$, which is the target density at the end of construction, represents the compactibility of the mix in laying operations until it reaches a value of air voids of around $8 \%[19,69,72]$.

The area under the densification curve between $\mathrm{N} 92$ and a number of gyrations corresponding to $98 \% \mathrm{Gmm}$ is associated to mix performance under traffic loading: the critical density of $98 \%$ represents 
the traffic post-compaction action during pavement service life until a final value of air voids of about $2 \%[71]$.

Mixtures with higher values of CDI/CFI show worse workability because they are difficult to compact, whereas higher values of TDI/TFI characterize asphalts with a better stability under traffic loads [68].

In this study, these indexes were calculated for the two mixes to obtain more detailed information on how the aged bitumen can modify asphalt mix workability and compatibility at different number of gyrations.

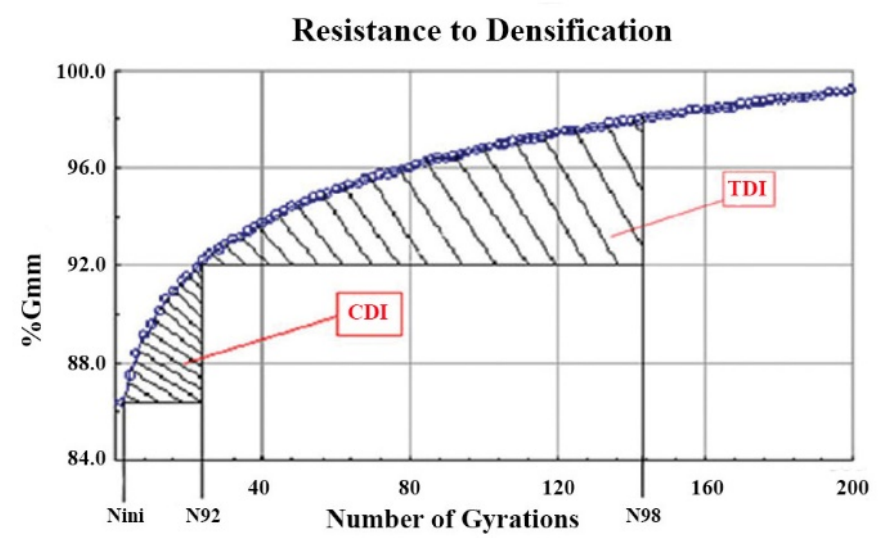

Resistance to Distortion

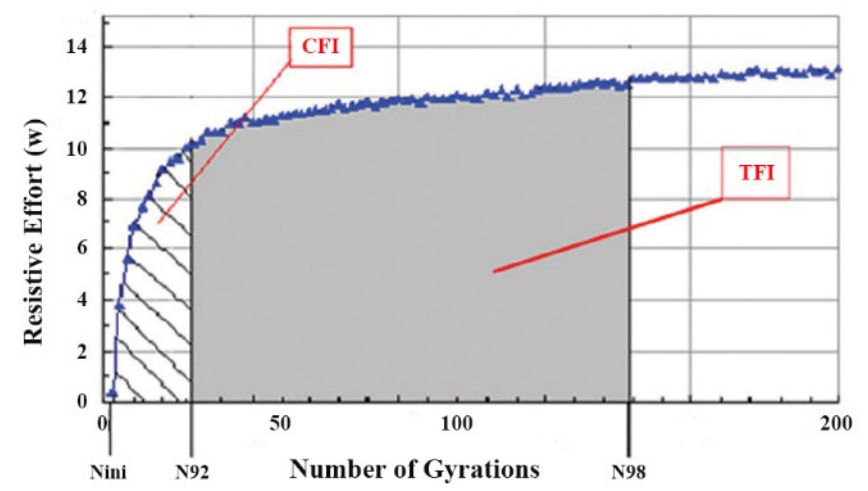

Figure A1. Densification indexes for mix resistance to densification and Traffic indexes for mix resistance to distortion.

\section{References}

1. Shin-Che Huang, S.C.; Di Benedetto, H. Advances in Asphalt Materials 1st Edition Road and Pavement Construction; Elsevier Science: Amsterdam, The Netherlands, 2015; Hardcover ISBN 9780081002698, eBook ISBN 9780081002711.

2. Caputo, P.; Loise, V.; Ashimova, S.; Teltayev, B.; Vaiana, R.; Oliviero Rossi, C. Inverse Laplace Transform (ILT) NMR: A powerful tool to differentiate a real rejuvenator and a softener of aged bitumen. Colloids Surf. A 2019, 574, 154-161. [CrossRef]

3. Rubio, M.C.; Martínez, G.; Baena, L.; Moreno, F. Warm mix asphalt: An overview. J. Clean. Prod. 2012, 24, 76-84. [CrossRef]

4. Sasol Wax Sasobit REDUX Factsheet. 2016. Available online: https://www.sasolwax.com/fileadmin/sasolwax/ documents/Asphalt\%20Additives/Asphalt_Additive_Sasobit_REDUX.pdf (accessed on 11 April 2020).

5. Rowe, G.M.; Baumgardner, G.L.; Reinke, G.; D'Angelo, J.; Anderson, D.A. Evaluation of the BBR test with mixtures containing waxes. In Proceedings of the Binder Expert Task Group Meeting, San Antonio, TX, USA, 14-15 September 2009. 
6. Lu, X.; Redelius, P. Effect of bitumen wax on asphalt mixture performance. Constr. Build. Mater. 2007, 21, 70. [CrossRef]

7. Sol-Sánchez, M.; Moreno-Navarro, F.; Rubio-Gámez, M.C. Study of Surfactant Additives for the Manufacture of Warm Mix Asphalt: From Laboratory Design to Asphalt Plant Manufacture. Appl. Sci. 2017, 7, 745. [CrossRef]

8. Caputo, P.; Abe, A.A.; Loise, V.; Porto, M.; Calandra, P.; Angelico, R.; Oliviero Rossi, C. The Role of Additives in Warm Mix Asphalt Technology: An Insight into their Mechanisms of Improving an Emerging Technology. Nanomaterials 2020, 10, 1202. [CrossRef] [PubMed]

9. Prowell, B.D.; Hurley, G.C.; Frank, B. Warm-Mix Asphalt: Best Practices, 2nd ed.; Quality Improvement Publication: Lanham, MD, USA, 2011.

10. Srikanth, G.; Kumar, R.; Vasudeva, R. A Review on Warm Mix Asphalt. In Proceedings of the National Conference: Advanced Structures, Materials and Methodology in Civil Engineering (ASMMCE-2018), NIT Jalandhar, India, 3-4 November 2018.

11. Caputo, P.; Ranieri, G.A.; Godbert, N.; Aiello, I.; Tagarelli, A.; Oliviero Rossi, C. Investigation of new additives to reduce the fume emission of bitumen during Asphalt Concrete Processing. Mediterr. J. Chem. 2018, 7, 259-266. [CrossRef]

12. EAPA. The Use of Warm Mix Asphalt_EAPA Position Paper; European Asphalt Pavement Association: Brussels, Belgium, 2014.

13. Oliviero Rossi, C.; Caputo, P.; Baldino, N.; Lupi, F.R.; Miriello, D.; Angelico, R. Effects of adhesion promoters on the contact angle of bitumen-aggregate interface. Int. J. Adhes. Adhes. 2016, 70, 297-303. [CrossRef]

14. Baldino, N.; Gabriele, D.; Oliviero Rossi, C.; Seta, L.; Lupi, F.R.; Caputo, P.; Falvo, T. Rheological effects on bitumen of polyphosphoric acid (PPA) addition. Constr. Build. Mater. 2013, 40, 397-404. [CrossRef]

15. Caputo, P.; Porto, M.; Calandra, P.; De Santo, M.P.; Oliviero Rossi, C. Effect of epoxidized soybean oil on mechanical properties of bitumen and aged bitumen. Mol. Cryst. Liq. Cryst. 2018, 675, 68-74. [CrossRef]

16. Oliviero Rossi, C.; Caputo, P.; Ashimova, S.; Fabozzi, A.; D’Errico, G.; Angelico, R. Effects of Natural Antioxidant Agents on the Bitumen Aging Process: An EPR and Rheological Investigation. Appl. Sci. 2018, 8, 1405. [CrossRef]

17. Porto, M.; Caputo, P.; Loise, V.; De Filpo, G.; Oliviero Rossi, C.; Calandra, P. Polysaccharides-Reinforced Bitumens: Specificities and Universality of Rheological Behavior. Appl. Sci. 2019, 9, 5564. [CrossRef]

18. Vaiana, R.; Iuele, T.; Gallelli, V.; Tighe, S. Warm mix asphalt by water-containing methodology: A laboratory study on workability properties versus micro-foaming time. Can. J. Civ. Eng. 2014, 41, 183-190. [CrossRef]

19. Vaiana, R.; Iuele, T.; Gallelli, V. Warm mix asphalt with synthetic zeolite: A laboratory study on mixes workability. Int. J. Pavement Res. Technol. 2013, 6, 562-569. [CrossRef]

20. Dessouky, S.; Pothuganti, A.; Walubita, L.F.; Rand, D. Laboratory Evaluation of the Workability and Compactability of Asphaltic Materials prior to Road Construction. J. Mater. Civ. Eng. 2013, 25, 810-818. [CrossRef]

21. Hesami, E.; Jelagin, D.; Kringos, N.; Birgisson, B. An empirical framework for determining asphalt mastic viscosity as a function of mineral filler concentration. Constr. Build. Mater. 2012, 35, 23-29. [CrossRef]

22. Gudimettla, J.M.; Cooley, L.A., Jr.; Brown, E.R. Workability of Hot-Mix Asphalt. Transp. Res. Rec. 2004, 1891, 229-237. [CrossRef]

23. Hunter, A.E.; Airey, G.D.; Collop, A.C. Aggregate Orientation and Segregation in Laboratory-Compacted Asphalt Samples. Transp. Res. Rec. 2004, 1891, 8-15. [CrossRef]

24. Yu, H.; Leng, Z.; Dong, Z.; Tan, Z.; Guo, F.; Yan, J. Workability and mechanical property characterization of asphalt rubber mixtures modified with various warm mix asphalt additives. Constr. Build. Mater. 2018, 175, 392-401. [CrossRef]

25. Miró, R.; Martínez, A.H.; Pérez-Jiménez, F.E.; Botella, R.; Álvarez, A. Effect of filler and content on the bituminous mastic behaviour under cyclic loads. Constr. Build. Mater. 2017, 132, 33-42. [CrossRef]

26. Cheng, Y.; Tao, J.; Jiao, Y.; Tan, G.; Guo, Q.; Wang, S.; Ni, P. Influence of the properties of filler on high and medium temperature performances of asphalt mastic. Constr. Build. Mater. 2016, 118, 268-275. [CrossRef]

27. Antunes, V.; Freire, A.C.; Quaresma, L.; Micaelo, R. Influence of the geometrical and physical properties of filler in the filler-bitumen interaction. Constr. Build. Mater. 2015, 76, 322-329. [CrossRef] 
28. Antunes, V.; Freire, A.C.; Quaresma, L.; Micaelo, R. Effect of the chemical composition of fillers in the filler-bitumen interaction. Constr. Build. Mater. 2016, 104, 85-91. [CrossRef]

29. Huang, B.; Shu, X.; Chen, X. Effects of mineral fillers on hot-mix asphalt laboratory-measured properties. Int. J. Pavement Eng. 2007, 8, 1-9. [CrossRef]

30. Khan, Z.A.; Al-Abdul Wahab, H.I.; Asi, I.; Ramadhan, R. Comparative study of asphalt concrete laboratory compaction methods to simulate field compaction. Constr. Build. Mater. 1998, 12, 373-384. [CrossRef]

31. Praticò, F.G.; Vaiana, R.; Moro, A. Dependence of Volumetric Parameters of Hot Mix Asphalts on Testing Methods. J. Mater. Civ. Eng. 2014, 26, 45-53. [CrossRef]

32. Praticò, F.G.; Vaiana, R. A study on volumetric versus surface properties of wearing courses. Constr. Build. Mater. 2013, 38, 766-775. [CrossRef]

33. Loeber, L.; Muller, G.; Morel, J.; Sutton, O. Bitumen in colloid science: A chemical, structure and rheological approach. Fuel 1998, 77, 1443-1450. [CrossRef]

34. Okan, S.; Dalim, K.P.; Emad, K. State of the Art Study on Aging of Asphalt Mixtures and Use of Antioxidant Additives. Adv. Civ. Eng. 2018, 2018, 3428961. [CrossRef]

35. Oliviero Rossi, C.; Caputo, P.; Loise, V.; Miriello, D.; Teltayev, B.; Angelico, R. Role of food grade additive in the high temperature performance of modified bitumens. Colloids Surf. A Phys. Eng. Asp. 2017, 592, 618-624. [CrossRef]

36. Ashimova, S.; Teltayev, B.; Oliviero Rossi, C.; Caputo, P.; Eskandarsefat, S. Organic-based recycling agents for road paving applications in cold-climate regions. Int. J. Pavement Eng. 2012, 24, 76-84. [CrossRef]

37. Oliviero Rossi, C.; Caputo, P.; De Luca, G.; Maiuolo, L.; Eskandarsefat, S.; Sangiorgi, C. 1H-NMR Spectroscopy: A Possible Approach to Advanced Bitumen Characterization for Industrial and Paving Applications. Appl. Sci. 2018, 8, 229. [CrossRef]

38. Caputo, P.; Loise, V.; Crispini, A.; Sangiorgi, C.; Scarpelli, F.; Oliviero Rossi, R. The efficiency of bitumen rejuvenator investigated through Powder X-ray Diffraction (PXRD) analysis and T2-NMR spectroscopy. Colloids Surf. A 2019, 571, 50-54. [CrossRef]

39. Yen, T.F.; Chilingarian, G.V. Asphalthenes and Asphalts; Elsevier: New York, NY, USA, 1994.

40. Calandra, P.; Caputo, P.; De Santo, M.P.; Todaro, L.; Turco Liveri, V.; Oliviero Rossi, C. Effect of additives on the structural organization of asphaltene aggregates in bitumen. Constr. Build. Mater. 2019, 199, $288-297$. [CrossRef]

41. Petersen, J.C. Chemical Composition of Asphalt as Related to Asphalt Durability: State of the Art. Transp. Res. Rec. 1984, 999, 13-30.

42. Read, J.; Whiteoak, D. The Shell Bitumen Handbook, 5th ed.; Hunter, R.N., Ed.; Thomas Telford Publishing: London, UK, 2003.

43. Sheu, E.Y.; Storm, D.A. Colloidal properties of asphaltenes in organic solvents. In Asphaltenes: Fundamentals and Applications; Sheu, E.Y., Mullins, O.C., Eds.; Plenum Press: New York, NY, USA, 1995; Chapter 1.

44. Yoon, S.; Durgashanker Bhatt, S.; Lee, W.; Lee, H.Y.; Jeong, S.Y.; Baeg, J.-O.; Wee Lee, C. Separation and characterization of bitumen from Athabasca oil sand. Korean. J. Chem. Eng. 2009, 26, 64-71.

45. ANAS. Special Tender Specifications. In Road Paving; Technical Standards: Rome, Italy, 2009.

46. Kennedy, T.W.; Huber, G.A.; Harrigan, E.T.; Cominsky, R.J.; Hughes, C.S.; Von Quintus, H.; Moulthrop, J.S. Superior Performing Asphalt Pavements (Superpave): The Product of the SHRP Asphalt Research Program; National Research Council: Washington, DC, USA, 1994.

47. Kuang, X.; Liu, G.; Dong, X.; Wang, D. Correlation between stress relaxation dynamics and thermochemistry for covalent adaptive networks polymers. Mater. Chem. Front. 2017, 1, 111-118. [CrossRef]

48. Calandra, P.; Nicotera, I.; Oliviero Rossi, C.; Turco Liveri, V. Dynamical properties of self-assembled surfactant-based mixtures: Triggering of 1D anomalous diffusion in bis(2-ethylhexyl) phosphoric acid/n-octylamine systems. Langmuir 2013, 29, 14848-14854. [CrossRef]

49. Calandra, P.; Turco Liveri, V.; Monia Ruggirello, A.; Licciardi, M.; Lombardo, D.; Mandanici, A. Anti-Arrhenian behaviour of conductivity in octanoic acid-bis(2-ethylhexyl)amine systems: A physico-chemical study. J. Mater. Chem. C 2015, 3, 3198-3210. [CrossRef]

50. Petrowsky, M.; Frech, R. Application of the compensated arrhenius formalism to dielectric relaxation. J. Phys. Chem. B 2009, 113, 16118-16123. [CrossRef] 
51. Loise, V.; Caputo, P.; Porto, M.; Teltayev, B.; Angelico, R.; Oliviero Rossi, C. Unravelling the role of a green rejuvenator agent in contrasting the aging effect on bitumen: A dynamics rheology, nuclear magnetic relaxometry and self-diffusion study. Colloids Surf. A 2020, 603, 125182. [CrossRef]

52. Cummings, P.T.; Evans, D.J. Nonequilibrium molecular dynamics approaches to transport properties and non-Newtonian fluid rheology. Ind. Eng. Chem. Res. 1992, 31, 1237-1252. [CrossRef]

53. Carvalho-Silva, V.H.; Coutinho, N.D.; Aquilanti, V. Temperature Dependence of Rate Processes Beyond Arrhenius and Eyring: Activation and Transitivity. Front. Chem. 2019, 7, 380. [CrossRef] [PubMed]

54. Scherer, G.W. Use of the Adam-Gibbs Equation in the Analysis of Structural Relaxation. J. Am. Ceram. Soc. 1984, 67, 504-511. [CrossRef]

55. Eyring, H. The activated complex in chemical reactions. J. Chem. Phys. 1935, 3, 107-115. [CrossRef]

56. Tyrrell, H.J.V.; Harris, K.R. Diffusion in Liquids; Butterworths: London, UK, 1984.

57. El Asjadi, S.; Nederpel, Q.A.; Cotiuga, I.M.; Picken, S.J.; Besseling, N.A.M.; Mendes, E.; Lommerts, B.J. Biopolymer scleroglucan as an emulsion stabilizer. Colloids Surf. A Physicochem. Eng. Asp. 2018, 546, 326-333. [CrossRef]

58. Byran, J.; Kantzas, A.; Bellehumer, C. Oil-viscosity predictions from low-field NMR measurements. SPE Reserv. Eval. Eng. 2005, 8, 44-52. [CrossRef]

59. Messaâdi, A.; Dhouibi, N.; Hamda, H.; Belgacem, F.B.M.; Adbelkader, Y.H.; Ouerfelli, N.; Hamzaoui, A.H. A New Equation Relating the Viscosity Arrhenius Temperature and the Activation Energy for Some Newtonian Classical Solvents. J. Chem. 2015, 2015, 163262. [CrossRef]

60. Polaczyk, P.; Huang, B.; Shu, X.; Gong, H. Investigation into Locking Point of Asphalt Mixtures Utilizing Superpave and Marshall Compactors. J. Mater. Civ. Eng. 2019, 31, 04019188. [CrossRef]

61. Bahia, H.U.; Friemel, T.P.; Peterson, P.A.; Russell, J.S.; Poehnelt, B. Optimization of constructibility and resistance to traffic: A new design approach for HMA using the superpave compactor. J. Assoc. Asph. Paving Technol. 1998, 67, 189-232.

62. Caputo, P.; Porto, M.; Loise, V.; Teltayev, B.; Oliviero Rossi, C. Analysis of mechanical performance of bitumen modified with waste plastic and rubber (SBR) additives by rheology and PGSE NMR experiments. Eurasian Chem. Technol. J. 2019, 21, 235-239. [CrossRef]

63. Caputo, P.; Shaikhah, D.; Porto, M.; Loise, V.; De Santo, M.P.; Oliviero Rossi, C. NMR Di_usiometry Spectroscopy, a Novel Technique for Monitoring the Micro-Modifications in Bitumen Ageing. Appl. Sci. 2020, 10, 5409. [CrossRef]

64. Oliviero Rossi, C.; Caputo, P.; Loise, V.; Ashimova, S.; Teltayev, B.; Sangiorgi, C. A New Green Rejuvenator: Evaluation of Structural Changes of Aged and Recycled Bitumens by Means of Rheology and NMR; Springer: Cham, Switzerland, 2019; pp. 177-182. [CrossRef]

65. Błażejowski, K.; Olszacki, J.; Peciakowski, H.; Wójcik-Wiśniewska, M. Testing of bitumen-aggregate affinity by various methods. In Proceedings of the 16th Eurasphalt \& Eurobitume Congress, Prague, Czech Republic, 1-3 June 2016.

66. Farcas, F. Étude d'une Méthode de Simulation du Vieillissement des Bitumes sur Route; LCPC Research Report CR21; LCPC: Paris, France, 1998.

67. Abdo, A.A.; Bayomy, F.; Masad, E.; Santi, M. Evaluation of Aggregate Structure Stability Using the Superpave Gyratory Compactor. In Proceedings of the Transportation Research Board 85th Annual Meeting, Washington, DC, USA, 22-26 January 2006.

68. Sanchez-Alonso, E.; Vega-Zamanillo, A.; Castro-Fresno, D.; Del Rio-Prat, M. Evaluation of compactibility and mechanical properties of bituminous mixes with warm additives. Constr. Build. Mater. 2011, 25, 2304-2311. [CrossRef]

69. Mo, L.; Li, X.; Fang, X.; Huurman, M.; Wu, S. Laboratory investigation of compaction characteristics and performance of warm mix asphalt containing chemical additives. Constr. Build. Mater. 2012, 37, 239-247. [CrossRef]

70. Kanitpong, K.; Sonthong, S.; Nam, K.; Martono, W.; Bahia, H.U. Laboratory Study on Warm Mix Asphalt Additives. In Proceedings of the Transportation Research Board 86th Annual Meeting, Washington, DC, USA, 21-25 January 2007.

71. Faheem, A.; Bahia, H.U. Using the Gyratory Compactor to Measure Mechanical Stability of Asphalt Mixtures; Wisconsin Highway Research Program Report, N. WHRP 05-02; Wisconsin Department of Transportation: Madison, WI, USA, 2004. 
72. Sadasivam, S. Evaluation of the Effects of Compaction Methods on the Predicted Performance of Superpave Mixtures. Master's Thesis, Graduate Faculty of North Carolina State University, Raleigh, NC, USA, 2004.

Publisher's Note: MDPI stays neutral with regard to jurisdictional claims in published maps and institutional affiliations.

(C) 2020 by the authors. Licensee MDPI, Basel, Switzerland. This article is an open access article distributed under the terms and conditions of the Creative Commons Attribution (CC BY) license (http://creativecommons.org/licenses/by/4.0/). 